$\underline{\text { Article }}$

\title{
Bringing Research Closer to Reality: Configurational Analysis and Practical International Business Research
}

\author{
Stav Fainshmidt ${ }^{1}$, ${ }^{\text {, Kira Haensel }}{ }^{1}$, Daniel S. Andrews ${ }^{2}$ \\ ${ }^{1}$ Florida International University, USA, ${ }^{2}$ Ivey Business School, Canada \\ Keywords: qualitative comparative analysis, causal complexity, methodology, configurational analysis, international business \\ https://doi.org/10.46697/001c.24381
}

\section{AIB Insights}

Vol. 21, Issue 2, 2021

\begin{abstract}
International business (IB) research focused on practical insights requires analytical techniques that come closer to reality by embracing complexity. In this article, we discuss Qualitative Comparative Analysis (QCA), a configurational technique researchers can leverage to study complex causal patterns in IB phenomena. We briefly review the basics of QCA, provide an example of how it can be applied to study practical IB issues, and outline the first steps for researchers situated at the intersection of IB practice and scholarship. Employing such techniques may make applied IB research even better positioned to make impactful contributions to practice and society.
\end{abstract}

\section{INTRODUCTION}

International business (IB) research aiming to advance actionable insights and a realistic understanding of cross-border and comparative phenomena requires the employment of research designs and analytical techniques that, to the extent possible, approximate the reality of doing business across borders or in distinct contexts (Fainshmidt, Witt, Aguilera, \& Verbeke, 2020). IB phenomena are inherently complex because, in addition to organizational phenomena being such in general (Fiss, 2007, 2011), crossing borders and engaging with diverse actors often render causal relationships not well suited for linear or variance-based explanations (Witt \& Jackson, 2016). As Furnari et al. (2020: 3) argue, "most of the"grand challenges" and "wicked problems" facing societal and organizational actors [...] are particularly known for their complex multifaceted nature."

However, most IB research, including that which is applied, relies on variance-based techniques and apparatus (Fainshmidt, Witt, Aguilera, \& Verbeke, 2020). To be sure, such techniques are highly useful and can offer valuable practical insights. Yet, if IB researchers strive to bring their empirics closer to reality, complementary approaches that embrace complexity rather than eschewing it are warranted. For instance, Judge, Fainshmidt, \& Brown III (2014) examine configurations of institutional characteristics, demonstrating several optimal models of capitalism for equitable wealth creation, while an abundance of prior studies typically focused on single, isolated institutional characteristics. Although both types of studies - configurational and variance-based - contribute to our understating of how institutional context shapes economic outcomes, the former better approximates reality because institutions tend to combine into gestalts.

Accordingly, in this article, we discuss Qualitative Comparative Analysis (QCA), a useful tool IB researchers can leverage to better understand IB phenomena. QCA enables inquiry into IB issues for which traditional techniques, such as regression, might not be well suited, and it can help uncover previously overlooked complex causal patterns in core IB phenomena.

In the following sections, we briefly review the tenets of QCA, particularly highlighting how these tenets help bring empirical analysis closer to reality. We acknowledge there are inherent weaknesses to QCA; hence our purpose here is not to claim QCA as superior to other approaches. Rather, we seek to support the extension of the methodological toolkit of IB researchers in a way we believe can make such research even more reflective of reality. Further, we provide an example of how the suggested approach can be applied to study practical IB issues. Our exposition highlights the versatility of QCA, explicating that it can be applied across multiple scientific strategies. Overall, we aim to propel the adoption of fresh methodological approaches for researchers situated at the intersection of IB practice and scholarship.

\section{QCA: SOME BASICS}

Management and IB scholars increasingly apply QCA to study organizational phenomena (Fainshmidt et al., 2020; Furnari et al., 2020). What makes QCA unique and valuable? In Table 1, we present a summary of key features and how they compare to traditional regression techniques. Although providing a primer on QCA is not our goal, we believe a few key features are worth mentioning. We refer 
Table 1. Brief Comparison between QCA and Regression Analysis

\begin{tabular}{|c|c|c|}
\hline & Regression & QCA \\
\hline $\begin{array}{l}\text { Explanatory } \\
\text { Approach }\end{array}$ & $\begin{array}{l}\text { - Explain variance in an outcome } \\
\text { - Example: Differences in profitability among } \\
\text { multinational firms }\end{array}$ & $\begin{array}{l}\text { - Explain the presence or absence of an outcome } \\
\text { condition } \\
\text { - Example: A subsidiary exhibiting a broad } \\
\text { stakeholder orientation (e.g., Crilly, 2011) }\end{array}$ \\
\hline $\begin{array}{l}\text { Nature of } \\
\text { relationships } \\
\text { between causes } \\
\text { and outcomes }\end{array}$ & $\begin{array}{l}\text { - Statistical: Assess the average effect of } \\
\text { variables on an outcome } \\
\text { - Example: When the R\&D investment to sales } \\
\text { ratio goes up by } 1 \% \text {, firm profitability goes up } \\
\text { by } 0.5 \%\end{array}$ & $\begin{array}{l}\text { - Set-theoretic: Identify the conditions or } \\
\text { configurations of conditions consistent with the } \\
\text { outcome } \\
\text { - Example: Combinations of human resource } \\
\text { management practices associated with high } \\
\text { subsidiary performance }\end{array}$ \\
\hline Operates on & $\begin{array}{l}\text { - Variables } \\
\text { - Example: Return on assets }\end{array}$ & $\begin{array}{l}\text { - Conditions or sets } \\
\text { - Examples: High performance, very high } \\
\text { performance, not low performance }\end{array}$ \\
\hline $\begin{array}{l}\text { Ability to } \\
\text { accommodate } \\
\text { complexity }\end{array}$ & $\begin{array}{l}\text { - Limited, usually via lower-order interaction } \\
\text { terms } \\
\text { - Example: The effect of a one-unit increase in } \\
\text { R\&D investment on firm performance is larger } \\
\text { as the size of the firm increases }\end{array}$ & $\begin{array}{l}\text { - Inherent } \\
\text { - Indicates potential complementarities, and multiple } \\
\text { configurations can be associated with the outcome } \\
\text { (see practical example in the text) }\end{array}$ \\
\hline
\end{tabular}

readers to numerous existing publications on that front for more details (e.g., Fiss, Marx, \& Cambré, 2013; Greckhamer, Furnari, Fiss, \& Aguilera, 2018; Misangyi et al., 2017; Ragin, 2008; Schneider \& Wagemann, 2012), including one focused on IB research (Fainshmidt et al., 2020).

QCA is rooted in Boolean Algebra and operates on conditions, not variables. Conditions are sets in which cases can be members or non-members to different degrees. Conditions can capture differences in kind (presence versus absence) and in degree (extent of presence/absence). By comparison, variables capture differences in values (continuous) or degree (categorical). Hence, multiple distinct conditions can be calibrated from the same variable. For instance, return-on-assets is a variable that can be calibrated into conditions such as high performance, very high performance, not poor performance, and normative performance (Fiss, 2011).

In traditional regression analysis, the goal is estimating the average change in the value of the outcome variable when the explanatory variable changes by one unit. In QCA, the goal is assessing the extent to which membership of cases (e.g., countries) in (configurations of) causal conditions (e.g., high state expenditures, developed equity markets, prevalent collective bargaining) is consistent with membership in a given outcome (e.g., equitable wealth creation) (Judge et al., 2014).

The output of QCA (solution) typically contains the configurations of conditions that are associated with the outcome, if the data imply such configurations. This is usually referred to as the sufficiency analysis - in the sense that, based on the data and counterfactuals (i.e., configurations that are logically possible but not exhibited by the data) considered in the analysis, the outcome is in place when the causal conditions are in place. QCA can also identify necessary conditions in the sense that the condition is in place when the outcome is in place.

The configurational nature of the output accommodates several important aspects of complex IB phenomena. For instance, "a given outcome may follow from several different combinations of causal conditions" (Ragin, 2008: 124). This possibility allows for conjunctural causation and equifinality. The former means that relevant causal conditions jointly explain an outcome, while the latter means that more than one combination of conditions can bring about the outcome (Furnari et al., 2020). Considering conjunctural causation implies that conditions may combine in complementary ways. Equifinality may allow for functional substitution to be identified, either at the condition or configuration level, such that a condition or combination of conditions act as an alternative pathway to the outcome vis-à-vis other conditions(s) (Fiss, 2011).

These notions are not captured well by traditional statistical techniques, and they make QCA highly flexible. It can work with large (Witt \& Jackson, 2016) and small samples (Ragin, 2008); inductive and deductive studies (Fainshmidt, Wenger, Pezeshkan, \& Mallon, 2019; Schneider \& Wagemann, 2012); typological and taxonomical approaches (Fiss, 2011); and multilevel data (Andrews, Fainshmidt, Gaur, \& Parente, 2021). Although our focus is on quantitative techniques, QCA originated to complement qualitative designs, so it is useful in such studies as well (Crilly, 2011).

\section{PRACTICAL EXAMPLE: DIVESTMENT FROM CHINA}

Suppose that an IB researcher wanted to know why multinational firms might divest their foreign subsidiaries operating in China. It is plausible that the subsidiary's poor performance makes a divestment decision more likely, but on its own, it is probably insufficient to explain the decision because MNC managers are likely to take a more holistic approach in making such strategic decisions. If the Chinese market's importance within the MNC's global revenue portfolio is high and the relations between the MNC's home country and China are amicable, poor subsidiary performance alone might not lead to a divestment decision. How- 


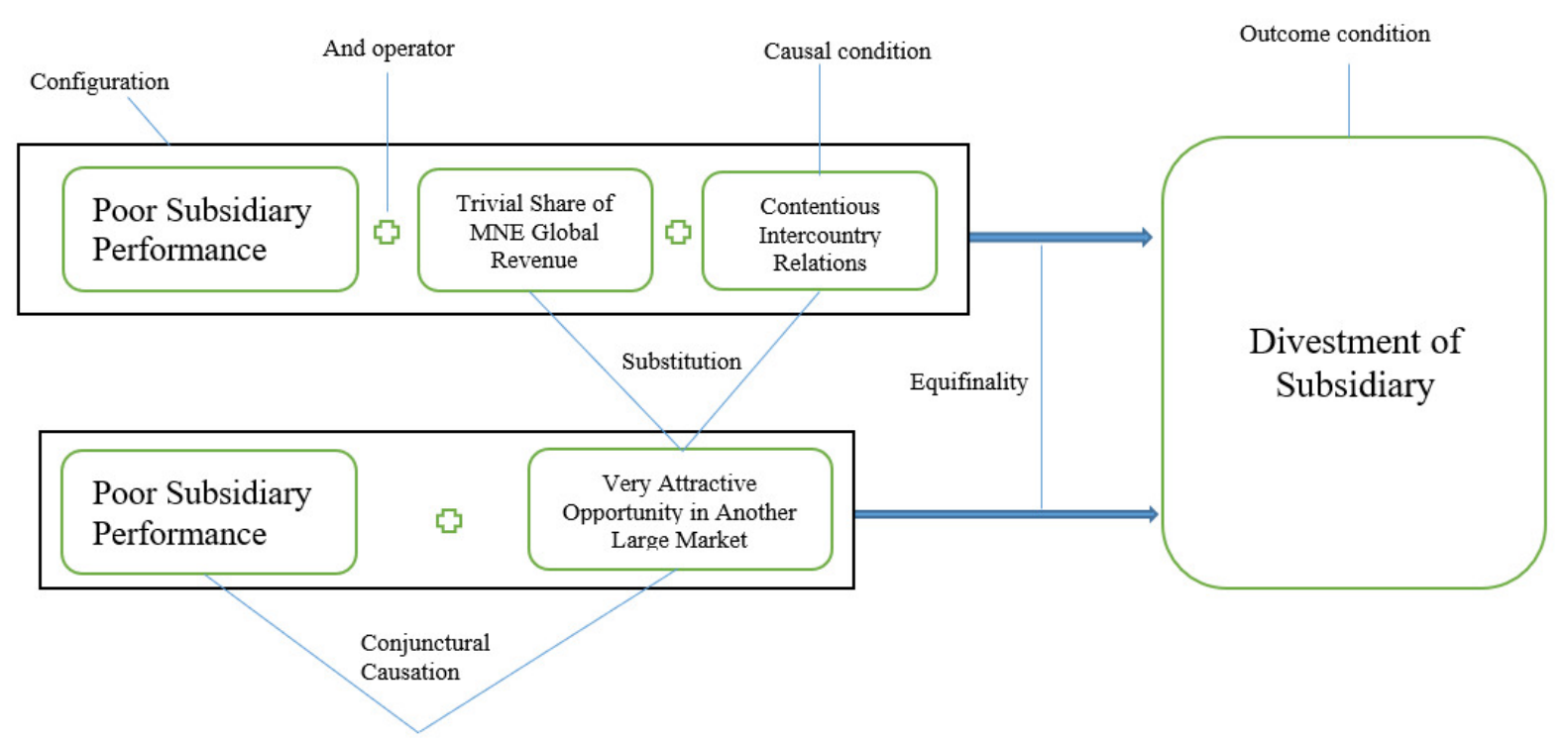

Figure 1. Hypothetical Scenarios for Subsidiary Divestment

ever, if the Chinese subsidiary accounts for a trivial share of the MNC's global revenue portfolio and intercountry relations are contentious, together with the subsidiary's poor performance, these conditions might be enough for MNC managers to divest the subsidiary. These scenarios illustrate the notions of conjunctural causation and complementarity. In Figure 1, we provide a graphical illustration to accompany this illustration.

Furthermore, opportunity cost considerations might make the divestment attractive, particularly if another subsidiary of the MNC in a large market, say India, is positioned to generate high growth and financial resources due to an emergent opportunity. Here, divestment might occur regardless of the importance of the Chinese subsidiary and the positive intercountry relations, as reallocating the divested resources represents a more economically viable long-term strategy. This scenario illustrates the notion of equifinality whereby functional substitution might take place. If the Chinese subsidiary were to perform well, the attractiveness of the investment option in the Indian market would have been comparatively lower.

Importantly, that poor subsidiary performance, low global portfolio importance, and contentious intercountry relations are a sufficient configuration for divestment does not mean that high performance, high global portfolio importance, and amicable intercountry relations are sufficient for staying in China. There could be conditions, such as a sufficiently attractive opportunity in another market, that bring about a divestment decision. This scenario illustrates the notion of causal asymmetry. Finally, if MNCs rarely divest subsidiaries that perform well, it could be that performing poorly might be a necessary but insufficient condition for divestment. This scenario would highlight the distinction between necessity and sufficiency relations between conditions.

Although we have chosen a simplified example - one that operates on a binary outcome and a dichotomization of causal conditions to facilitate narrative clarity - employ- ing QCA enables a more realistic exposition and discourse of the holistic and complex causal patterns implied by managerial decisions (Andrews et al., 2021), in this case, the divestment decision. Employing variance-based techniques, such as regression, would make uncovering such patterns essentially untenable, particularly given the challenges associated with higher-order interaction terms (Vis, 2012).

\section{FIRST STEPS FOR THE CONFIGURATIONALLY INCLINED}

There are several excellent primers and books on the QCA technique, as referenced earlier. Further, applying QCA is possible with several software applications (e.g., STATA, fsQCA, R). A free version of fsQCA by Charles Ragin and a manual explaining how to work the application (and the workings of QCA more broadly) are available for download: http://www.socsci.uci.edu/ cragin/fsOCA/software.shtml.

Additional readings and resources can be found at: https://compasss.org/. As the popularity of QCA grows in IB scholarship, there are also expert resources to draw upon, such as QCA methods clinics and masterclasses organized by the Annual AIB Conference.

In terms of conducting QCA, there are several stages researchers ought to follow. First, the sample must be theoretically relevant, and the configurational model - namely, the causal conditions and outcome - should be selected based on prior literature and theory. For further guidance on these aspects, see Greckhamer et al. (2018).

Next, QCA requires that raw data be calibrated into conditions or sets based on theoretical and contextual knowledge of the data and phenomena at hand. The goal is to capture the degree of membership or non-membership of cases (e.g., firms) in theoretically relevant conditions (e.g., high firm performance). Calibrated values range from 0 to 1 , with the former indicating full non-membership and the latter full membership in a set or condition. The crossover point, 
calibrated as 0.5 , indicates a situation where it is not clear whether a case is a member or non-member of a set. For instance, if prior research indicates that MNE managers make subsidiary divestment decisions based on return on investment (ROI) relative to industry peers, poor subsidiary performance can be calibrated as follows: Subsidiaries with ROI at the $25^{\text {th }}$ industry percentile or worse can be full members of the poor performance set (1), subsidiaries with median or better ROI can be full non-members of the set (0), and subsidiaries with ROI between the $25^{\text {th }}$ percentile and the median can be partial members of the set (calibrated between 0.5 and 1), proportionally. This is simply an illustration of the concept of calibration. Please consult the primers referenced earlier for proper guidelines on how to calibrate raw data.

Once data is calibrated into conditions, it is possible (and usually desired) to conduct a necessity analysis, which indicates any necessary conditions. Further, to identify the configurations associated with the outcome - the sufficiency analysis - the calibrated data are mapped onto a truth table. A truth table contains all logically possible configurations of conditions as well as "how consistently empirically observed configurations are linked to the outcome" (Greckhamer et al., 2018: 489). The researcher then specifies a consistency threshold (how consistent a configuration must be with the outcome to be retained) and a frequency threshold (how many cases are needed to retain a configuration), among other important specifications detailed in the primers. Based on these specifications, a minimization process ensues, resulting in solutions and fit indicators to evaluate them. Again, there is excellent guidance on evaluating, interpreting, and reporting QCA procedures and findings in the literature cited in this article.

\section{CONCLUSION}

The reality is that many IB phenomena are complex, but traditional IB research methods are usually not. As Fainshmidt et al. (2020: 455) succinctly note, "The mismatch between the nature of the empirical phenomena studied on the one hand, and hypothesis formulation and empirical methods deployed on the other, explains why many quantitative empirical studies in IB are overly reductionist, relying on hypotheses that assume linear (or simple, curvilinear), unifinal, and symmetrical effects."

We hope that this article stimulates more applied IB research, leveraging QCA to bring scholarly efforts closer to the reality of IB. The flexibility of QCA and its ability to accommodate complexity make it a particularly useful tool for studying Grand Challenges tied to the United Nation's Sustainability Development Goals, which are "broad based and not necessarily capable of solution" (Buckley, 2020: 2). For instance, agricultural sustainability is of increasing importance to IB scholars. At the same time, pandemics are disturbing MNE operations (Delios, Perchthold, \& Capri, 2021; Menzies \& Raskovic, 2020), shaping global migration (Hajro, Caprar, Zikic, \& Stahl, 2021), and propelling populist movements (Hartwell \& Devinney, 2021). While such issues are transforming the global landscape (Zahra, 2021), they are highly complex and difficult to simplify for analytical purposes (Bazel-Shoham \& Shoham, 2020). Employing a wider range of methodological tools that come closer to the reality of such phenomena may make IB research even better positioned to make impactful contributions to practice and society.

\section{ABOUT THE AUTHORS}

Stav Fainshmidt is an associate professor and the Knight Ridder Eminent Scholar Chair in International Business at the College of Business, Florida International University. His research interests include institutions and governance, organizational capabilities, and research methods. He received his Ph.D. in business administration (strategic management and international business) from old Dominion University.

Kira Haensel is a doctoral student in strategic management and international business at the Florida International University College of Business. Her research examines crisis management and the antecedents and consequences of global corporate sustainability activities, particularly at the intersection of corporate governance and societal impact.

Daniel Andrews is an Assistant Professor of International Business at the Ivey Business School of Western University. His research interests are in global strategy with a focus on foreign subsidiary management and collaborative strategy. He has published in several leading academic journals and regularly serves on the review board for international business and strategy outlets. He received his Ph.D. from Florida International University.

Submitted: May 13, 2021 EDT, Accepted: May 20, 2021 EDT 


\section{REFERENCES}

Andrews, D. S., Fainshmidt, S., Gaur, A., \& Parente, R. 2021. Configuring knowledge connectivity and strategy conditions for foreign subsidiary innovation. Long Range Planning. https://doi.org/10.1016/ j.lrp.2021.102089.

Bazel-Shoham, O., \& Shoham, A. 2020. Rethinking Overseas Production: The Case of COVID-19 and Negative Externality. AIB Insights, 20(3): 17690.

Buckley, P. J. 2020. International Business Research and the World Investment Report: "Big Questions" and Grand Challenges. AIB Insights, 20(4): 179-187.

Crilly, D. 2011. Predicting stakeholder orientation in the multinational enterprise: A mid-range theory. Journal of International Business Studies, 42(5): 694-717.

Delios, A., Perchthold, G., \& Capri, A. 2021. Cohesion, COVID-19 and contemporary challenges to globalization. Journal of World Business, 56(3): 101197.

Fainshmidt, S., Wenger, L., Pezeshkan, A., \& Mallon, M. R. 2019. When do dynamic capabilities lead to competitive advantage? The importance of strategic fit. Journal of Management Studies, 56(4): 758-787.

Fainshmidt, S., Witt, M. A., Aguilera, R. V., \& Verbeke, A. 2020. The contributions of qualitative comparative analysis (QCA) to international business research. Journal of International Business Studies. https://doi.org/10.1057/s41267-020-00313-1.

Fiss, P. C. 2007. A set-theoretic approach to organizational configurations. Academy of Management Review, 32(4): 1180-1198.

Fiss, P. C. 2011. Building better causal theories: A fuzzy set approach to typologies in organization research. Academy of Management Journal, 54(2): 393-420.

Fiss, P. C., Marx, A., \& Cambré, B. 2013. Configurational theory and methods in organizational research: Introduction. Emerald Group Publishing Limited. https://doi.org/10.1108/s0 733-558x(2013)0000038005.

Furnari, S., Crilly, D. C., Misangyi, V. F., Greckhamer, T., Fiss, P. C., et al. 2020. Capturing Causal Complexity: Heuristics for Configurational Theorizing. Academy of Management Review. https://doi.org/10.5465/amr.2019.0298.
Greckhamer, T., Furnari, S., Fiss, P. C., \& Aguilera, R. V. 2018. Studying configurations with qualitative comparative analysis: Best practices in strategy and organization research. Strategic Organization, 16(4): 482-495.

Hajro, A., Caprar, D. V., Zikic, J., \& Stahl, G. K. 2021. Global migrants: Understanding the implications for international business and management. Journal of World Business, 56(2): 101192.

Hartwell, C. A., \& Devinney, T. 2021. Populism, political risk, and pandemics: The challenges of political leadership for business in a post-COVID world. Journal of World Business, 56(4): 101225.

Judge, W. Q., Fainshmidt, S., \& Brown III, J. L. 2014. Which model of capitalism best delivers both wealth and equality? Journal of International Business Studies, 45(4): 363-386.

Menzies, J., \& Raskovic, M. 2020. Taming COVID-19 through social resilience: A meta-capability policy framework from Australia and New Zealand. $\boldsymbol{A I B}$ Insights, 20(3): 18165 .

Misangyi, V. F., Greckhamer, T., Furnari, S., Fiss, P. C., Crilly, D., et al. 2017. Embracing causal complexity: The emergence of a neo-configurational perspective. Journal of Management, 43(1): 255-282.

Ragin, C. C. 2008. Redesigning social inquiry: Fuzzy sets and beyond. Chicago: University of Chicago Press. https://doi.org/10.7208/chicago/ 9780226702797.001.0001.

Schneider, C. Q., \& Wagemann, C. 2012. Set-theoretic methods for the social sciences: $A$ guide to qualitative comparative analysis. Cambridge University Press. https://doi.org/10.1017/ cbo9781139004244.

Vis, B. 2012. The comparative advantages of fsQCA and regression analysis for moderately large- $\mathrm{N}$ analyses. Sociological Methods \& Research, 41(1): 168-198.

Witt, M. A., \& Jackson, G. 2016. Varieties of capitalism and institutional comparative advantage: A test and reinterpretation. Journal of International Business Studies, 47(7): 778-806.

Zahra, S. A. 2021. International entrepreneurship in the post Covid world. Journal of World Business, 56(1): 101-143. 